\title{
Downregulation of serum metabolite GTA-446 as a novel potential marker for early detection of colorectal cancer
}

\author{
Tsuyoshi Hata ${ }^{1,3}$, Ichiro Takemasa ${ }^{\star 2,3}$, Hidekazu Takahashi ${ }^{1}$, Naotsugu Haraguchi ${ }^{1}$, Junichi Nishimura ${ }^{1}$, \\ Taishi Hata ${ }^{1}$, Tsunekazu Mizushima ${ }^{1}$, Yuichiro Doki ${ }^{1}$ and Masaki Mori ${ }^{1}$ \\ ${ }^{1}$ Department of Surgery, Gastroenterological Surgery, Graduate School of Medicine, Osaka University, 2-2, Yamadaoka, Suita, \\ Osaka 565-0871, Japan and 'Department of Surgery, Surgical Oncology and Science, Sapporo Medical University, S1 W17, \\ Chuo-ku, Sapporo, Hokkaido 060-8556, Japan
}

Background: We previously reported that GTA-446 may be a useful biomarker for early detection of colorectal cancer. In the present study, we confirmed the clinical feasibility of GTA-446 as a screening tool for colorectal cancer with a novel measurement system developed for clinical use. We also improved sensitivity by analysing GTA-446 levels according to gender.

Methods: Serum samples were collected from 225 colorectal cancer patients and 916 healthy volunteers to measure GTA-446 levels by flow injection analysis-mass spectrometry.

Results: GTA-446 levels were downregulated in colorectal cancer patients compared with the healthy volunteers, and in females compared with the males in both groups. Receiver operating characteristic curve analysis revealed an optimal cut-off of $2.72 \mu \mathrm{moll}^{-1}$ in males and $1.87 \mu \mathrm{mol} \mathrm{I}^{-1}$ in females, with a large area under the curve of 0.89-0.93. The sensitivity and specificity were $90.4 \%$ and $84.9 \%$ for males, $85.2 \%$ and $80.5 \%$ for females, and $83.3 \%$ and $84.8 \%$ for all subjects, respectively.

Conclusions: GTA-446 is a clinically relevant biomarker for colorectal cancer with high sensitivity when analysed by gender. Thus, GTA-446 is a promising tool for primary colorectal cancer screening to identify populations at a higher risk of colorectal cancer, with an emphasis on early detection.

Colorectal cancer (CRC) is one of the most prevalent cancers worldwide; with $\sim 1.2$ million new cases and 600000 deaths annually it is the third most common cancer and the fourth most common cause of death by cancer (Brenner et al, 2014; Abbasi et al, 2015; Torre et al, 2015). Early-stage detection by effective and easily implemented screening would likely reduce the number of deaths associated with CRC. A simple and non-invasive test with high sensitivity to CRC, even in the early stages, would increase screening adherence rates and improve treatment outcomes.

In 2010, we reported the results of an international joint metabolome research study that identified a potential predictive marker for CRC (Ritchie et al, 2010a). The report described a family of novel circulating long-chain (28-carbon) hydroxy fatty acid metabolites referred to as hydroxylated polyunsaturated ultralong-chain fatty acids (hPULC-FAs) or gastrointestinal tract acids (GTAs). Serum levels of some of these metabolites were lower in CRC patients than disease-free controls. We focused on GTA-446 $\left(\mathrm{C}_{28} \mathrm{H}_{46} \mathrm{O}_{4}\right.$, molecular weight $\left.446 \mathrm{kDa}\right)$ as the most promising. As GTA-446 levels were lower in the serum of CRC patients compared to the healthy controls, and the levels remained consistent before and after surgical removal of tumours, GTA-446 is considered to be a novel and distinct detection marker that reflects susceptibility

\footnotetext{
*Correspondence: Professor I Takemasa; E-mail: itakemasa@sapmed.ac.jp

${ }^{3}$ These authors contributed equally to this work.
}

Received 30 November 2016; revised 14 April 2017; accepted 16 May 2017; published online 20 June 2017

C) 2017 Cancer Research UK. All rights reserved 0007-0920/17 
to CRC but is not influenced by the presence of the disease (Ritchie et al, 2010a, b). Previously, GTA-446 levels were measured by liquid chromatography-tandem mass spectrometry (LS-MS/MS) in a research setting. However, the preparation and measurements involved in this method are not suitable for a high volume setting. To adapt the method to clinical settings, flow injection analysismass spectrometry (FIA-MS/MS), which has the advantage of high throughput, was developed and is already available in clinical practice (Ritchie et al, 2013).

Recent studies have shown that CRC can be classified into subtypes (Schlicker et al, 2012; Budinska et al, 2013; De Sousa et al, 2013; Marisa et al, 2013; Sadanandam et al, 2013; Roepman et al, 2014; Guinney et al, 2015). In 2015, the subtypes were described by international consensus and named 'consensus molecular subtypes' (CMSs) (Guinney et al, 2015). In these studies, the proportion of males and females carrying the CRC CMSs varied, indicating gender differences in CRC development. Furthermore, not only genetic and epigenetic, but also hormonal and socio-cultural differences may affect CRC carcinogenesis (Kim et al, 2015). Therefore, we aimed to investigate the clinical feasibility of the GTA-446 test as a novel CRC screening tool with a highthroughput method by analysing serum levels according to gender.

\section{MATERIALS AND METHODS}

Study design. Samples were collected from an observational cohort comprising 225 CRC patients (136 men, 89 women) who underwent colorectal surgery from April 2012 to September 2014 at Osaka University Hospital. Samples were screened for patients who had been histologically diagnosed with CRC at admission and discharge (pre-surgery and post-surgery). The distribution of tumour location was as follows: caecum, $n=22(9.8 \%)$; ascending colon, $n=34$ (15.1\%); transverse colon, $n=14(6.2 \%)$; descending colon, $n=14$ (6.2\%), sigmoid colon, $n=60$ (26.7\%); and rectum, $n=81(36.0 \%)$. The distribution of disease stage was as follows: stage $0, n=21(9.3 \%)$; stage I, $n=70(31.1 \%)$; stage II, $n=49$ $(21.8 \%)$; stage III, $n=71(31.6 \%)$; stage IV, $n=13$ (5.8\%); and stage not available, $n=1(0.4 \%)$. This study was approved by the Medical Ethics Board of Osaka University Hospital (ethics board number 213). All subjects provided written informed consent prior to participation.

As a control group, samples from 916 healthy volunteers (567 men, 349 women) matched to the CRC group were obtained from BML. (Tokyo, Japan). These volunteers provided written informed consent, and the samples were collected by BML in accordance with an ethically approved clinical trial protocol. 'Healthy' was defined as no treatment for cancer and no history of cancer as confirmed by a medical interview.

All blood samples were extracted under fasting conditions. Serum samples were prepared in vacutainer blood collection tubes with serum separator by allowing the blood sample to clot and then centrifuging. All samples were stored at $-80{ }^{\circ} \mathrm{C}$ until analysis.

Mass spectrometry. Serum samples were shipped frozen to Phenomenome Laboratory Services. (Saskatoon, Canada) for analysis. Briefly, serum was extracted by liquid-liquid extraction, and analysed by measuring the standard curve of GTA-446 levels and quality control samples using FIA-MS/MS. GTA-446 concentrations were quantitatively extrapolated from the GTA446 standard curve.

Statistical analysis. All data were expressed as the mean \pm s.d. Statistical differences between groups were analysed by the Student's $t$-test for continuous variables and $\chi^{2}$ test for others. Area under the curve (AUC) was calculated by receiver operating characteristic (ROC) analysis, and the cut-off value was set as the value that gives the point closest to $(0,1)$ on the ROC curve. All statistical analyses were performed using JMP version 11.0.0 (SAS Institute, Cary, NC, USA). $P<0.05$ was considered significant.

\section{RESULTS}

GTA-446 distribution in CRC patients and healthy volunteers. The distributions of GTA-446 levels in CRC patients and healthy volunteers as determined by mass spectrometry are shown in Figure 1A. The mean GTA-446 level in the CRC group was $1.52 \mu \mathrm{moll}^{-1}$, which was significantly lower than that of the control group $\left(3.44 \mu \mathrm{moll}^{-1}, P<0.0001\right)$.

Differences in GTA-446 levels by gender are shown in Figure 1B. Significant differences were found between the control and CRC groups in both males (3.96 vs $1.59 \mu \mathrm{moll}^{-1}$, respectively, $P<0.0001)$ and females (2.61 vs $1.35 \mu \mathrm{moll}^{-1}$, respectively, $P<0.0001)$. In the control group, the distribution of GTA-446 levels was shifted to the left in females compared to males. Accordingly, GTA-446 levels in the control group were higher in males $\left(3.96 \mu \mathrm{moll}^{-1}\right)$ than females $\left(2.61 \mu \mathrm{moll}^{-1}, P<0.0001\right.$, Figure 1C). This tendency of females to have lower levels of GTA446 was also evident in the CRC group (males, $1.59 \mu \mathrm{moll}^{-1} v \mathrm{~s}$ females, $1.35 \mu \mathrm{moll}^{-1} ; P<0.04$, Figure 1D). Taken together, these data indicate that GTA-446 expression was downregulated in the CRC group compared with the healthy control group, regardless of gender, and GTA-446 levels were lower in females than in males.

Effect of tumour burden on GTA-446 levels. We previously reported that serum concentrations of GTA-446 are not influenced by surgical removal of CRC tumours. To validate this finding and determine whether gender has an effect, GTA-446 levels were measured in CRC patients before and after surgery. The analysis excluded patients who underwent perioperative chemotherapy or chemoradiotherapy $(n=16)$ or surgery as an additional treatment after endoscopic resection $(n=16)$. Consequently, 193 perioperative subjects were analysed. GTA-446 levels were not significantly different before and after surgery in either males (1.62 vs $1.34 \mu \mathrm{moll}^{-1}$, respectively, $P=0.0731$; Figure $2 \mathrm{~A}$ ) or females (1.36 vs $1.13 \mu \mathrm{moll}^{-1}$, respectively, $P=0.0836$; Figure $2 \mathrm{~B}$ ). These results suggest that GTA-446 levels reflect the susceptibility to CRC rather than the tumour burden. To confirm this finding, preoperative GTA-446 levels were compared according to the disease stage. No significant difference was found between patients with stage 0 -II (localised) disease and those with stage III-IV (regional or metastatic) disease (Figure 2C).

Cut-off analysis according to gender. To investigate whether GTA-446 levels can be used to predict an individual's risk of CRC and classify them into high- or low-risk groups, cut-off analyses were performed based on gender. For males, the AUC was 0.93 and the cut-off value $2.72 \mu \mathrm{moll}^{-1}$ (Figure $3 \mathrm{~A}$ ). The sensitivity and specificity were $90.4 \%$ and $84.8 \%$, respectively. For females, the AUC was 0.89 and the cut-off value $1.87 \mu \mathrm{moll}^{-1}$ (Figure 3A). The sensitivity and specificity were $85.2 \%$ and $80.5 \%$, respectively. Finally, to account for the risk of CRC by combining the two independent factors GTA-446 level and gender, we performed multiple logistic regression analysis with GTA-446 level and gender as variables. The AUC was 0.91 (Figure 3B), and the sensitivity and specificity $83.3 \%$ and $84.8 \%$, respectively.

\section{DISCUSSION}

The faecal occult blood test (FOBT) is a widely used method of screening for CRC on the basis of previous evidence that a regular FOBT can reduce the incidence of cancer deaths (Mandel et al, 1993; Hardcastle et al, 1996; Kronborg et al, 1996; Tokunaga et al, 

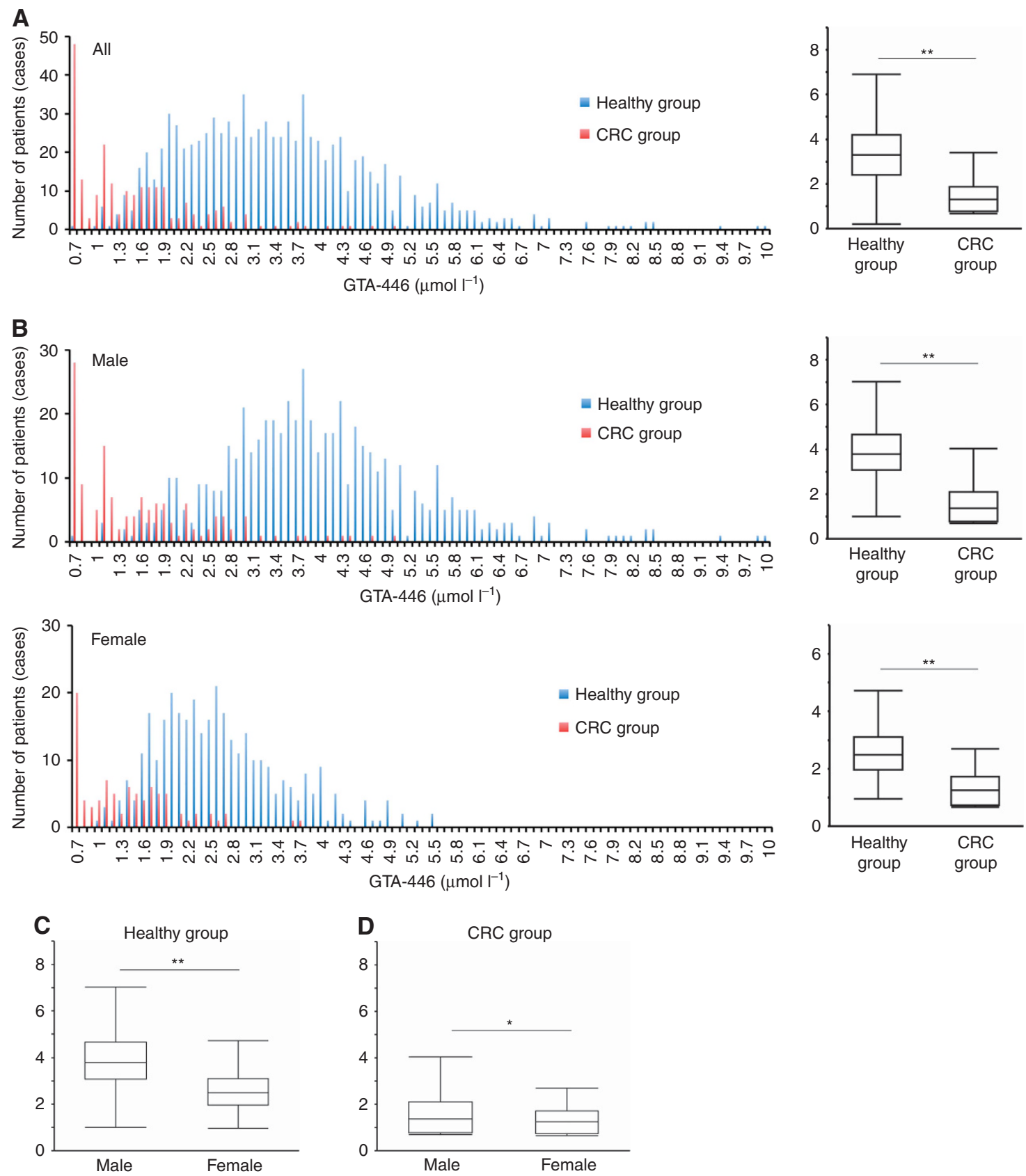

Figure 1. Comparison of GTA-446 levels. (A) Left: distribution of GTA-446 levels in the control (blue) and CRC groups (red). Right: comparison of GTA-446 levels between the two groups. (B) Left: distribution of GTA-446 levels in both groups by gender (top, males; bottom, females). Right: comparison of GTA-446 levels between both groups by gender (top, males; bottom, females). (C) Comparison of GTA-446 levels in males and females in the control and (D) CRC groups. The box indicates the range from the first quartile (Q) to the third $Q$. The short horizontal line indicates the maximum value (upper) and the minimum value (lower) in the interval from $1 \mathrm{Q}-(I Q R \times 1.5)$ to $3 \mathrm{Q}+(1 \mathrm{QR} \times 1.5)$ excluding outliers. IQR, interquartile range. ${ }^{\star} P<0.05,{ }^{\star \star} P<0.0001$.

2017); it has a sensitivity and specificity of $37.1-79.4 \%$ and 86.7-97.7\%, respectively (Allison et al, 1996). Owing to the low sensitivity of the FOBT, novel screening tests are now being investigated internationally (Ahlquist et al, 2000; Srivastava et al, 2001; Kim et al, 2003; Imperiale et al, 2004, 2014; Muller et al, 2004; Song et al, 2004; Solmi et al, 2006; Ma et al, 2009; Ahlquist et al, 2012; Toth et al, 2012; Yoshioka et al, 2014; Toiyama et al, 2016). The National Polyp Study revealed that colonoscopic polypectomy is associated with a $53 \%$ reduction in mortality from CRC, which definitively supports the widespread use of regular screening colonoscopy (Zauber et al, 2012). However, CRC deaths still occur with a fixed probability even if surveillance colonoscopy is performed (Zauber et al, 2012). Thus, more sophisticated screening is required for efficient colonoscopy. In particular, the detection of advanced polyps in the early phase of CRC is essential and should be verified by a large-scale prospective study with a high-sensitivity marker.

In 2014, the United States Food and Drug Administration approved two experimental tests for CRC detection: Epi proColon (Epigenomics, Berlin, Germany) and Cologuard (Exact Sciences, Madison, WI, USA). The former is a blood test that detects methylation of SEPT9. Kinga et al reported that the sensitivity and 
specificity of Epi proColon for CRC are 95.6\% and 84.8\%, respectively (Toth et al, 2012). On the other hand, Cologuard is a stool multitarget DNA test that detects KRAS mutations, aberrant
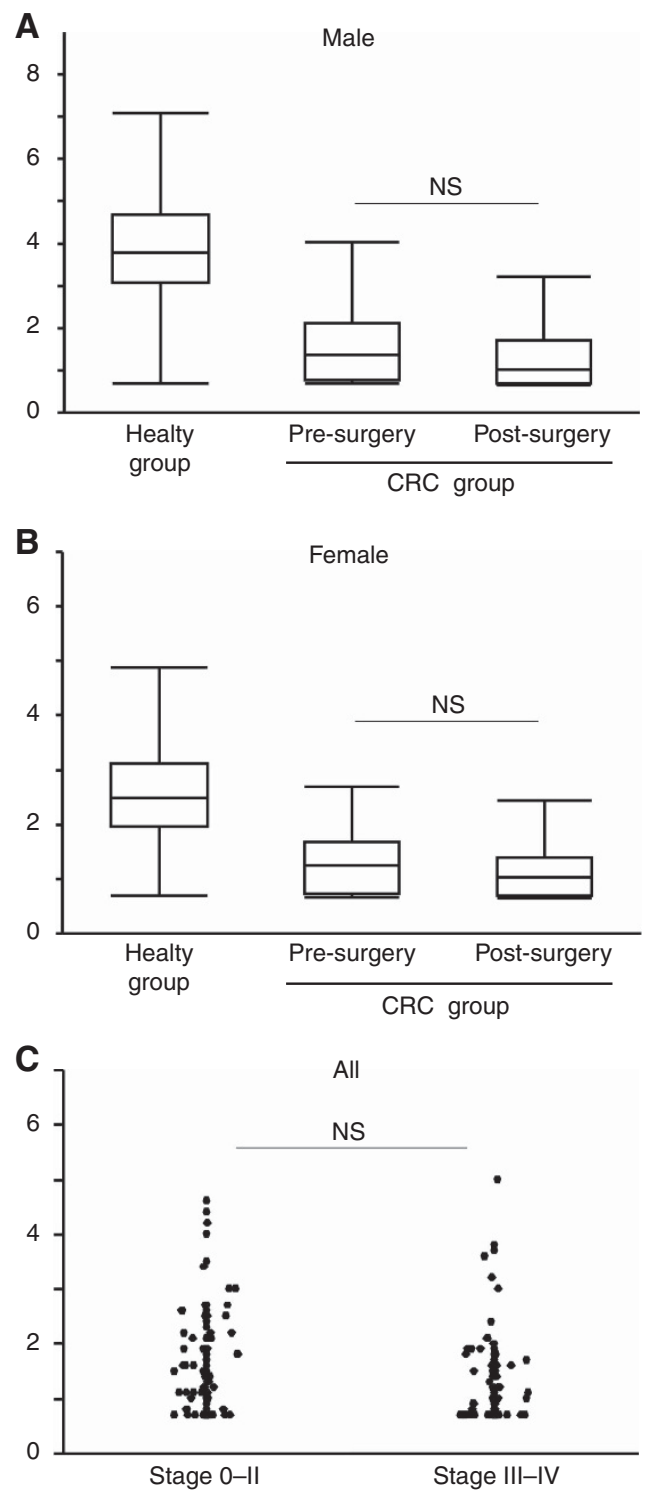

Figure 2. Pre-operative and postoperative GTA-446 levels. (A) Males and (B) females with CRC. (C) According to tumour stage. The box indicates the range from the first quartile (Q) to the third $\mathrm{Q}$. The short horizontal line indicates the maximum value (upper) and the minimum value (lower) in the interval from $1 Q-(I Q R \times 1.5)$ to $3 Q+(1 Q R \times 1.5)$ excluding outliers. IQR, interquartile range; NS, not significant.
NDRG4 and BMP3 methylation, and $\beta$-actin. Imperiale et al (2014) compared the sensitivity of FOBT to Cologuard as a stool biomarker for CRC. They found that the sensitivity of Cologuard for CRC (92.3\%) was superior to that of FOBT (73.8\%). Although the sensitivity of these tests is high, both methods are based on detecting tiny changes in cancer tissue. As both techniques depend on tumour burden, whether they can reliably identify small tumours or early disease is unclear. Given the results of the National Polyp Study (Zauber et al, 2012), a different screening method with higher prediction or earlier detection of CRC is desired.

Most of the biological markers included in previous studies depend on the presence of cancer; in these tests, a 'positive' result would be the detection of blood in FOBT, the upregulation of serum tumour markers (e.g., CEA and CA19-9) in blood testing, or the presence of changes indicating cancer in stool-based DNA testing. In contrast, consistent with previous studies on GTA-446 (Ritchie et al, 2010a, b), our study demonstrated that GTA-446 levels are downregulated in CRC patients compared with the healthy controls, and that no correlation exists between serum GTA-446 levels and disease stage or tumour burden. Considering these findings together, GTA-446 does not reflect the presence of a tumour, but susceptibility to CRC, and leads to identifying highrisk CRC patients with high sensitivity. This is a completely different concept from that of conventional tumour markers. In other words, downregulation of GTA-446 may indicate an imbalance in homoeostasis that could lead to the development of CRC. This is supported by the finding that patients who have been diagnosed with CRC at least once have a higher incidence of secondary CRC (Green et al, 2002; Winawer et al, 2003). Because GTA-446 can specify high-risk patients accurately using blood samples, it has high clinical importance for encouraging colonoscopy. Ritchie et al (2013) reported that the CRC incidence rate in patients undergoing colonoscopy with low GTA-446 levels was more than six times higher than that with high GTA-446 levels in a prospective setting. Therefore, GTA-446 could provide information about an individual's risk of CRC, even from a young period, and be the evidence needed to recommend colonoscopy for those at high-risk based on GTA-446 levels. Ritchie et al (2011) also revealed the function of GTA-446 in apoptotic and antiinflammatory activity through regulation of the NF- $\kappa \beta$ pathway. Thus, we propose that exogenous upregulation of GTA-446 can be exploited to prevent the development of CRC in susceptible individuals in the future. In addition, as screening programs for early detection generally target healthy people, FIA-MS/MS should be suitable for routine clinical use in this population because it is high throughput and requires only a blood sample. We think that the method would drive GTA-446 to be an effective tool for primary cancer screening.

In the current study, gender differences were observed in the distribution of GTA-446. In recent years, the biological differences in $\mathrm{CRC}$ according to gender have gained attention. CEA and
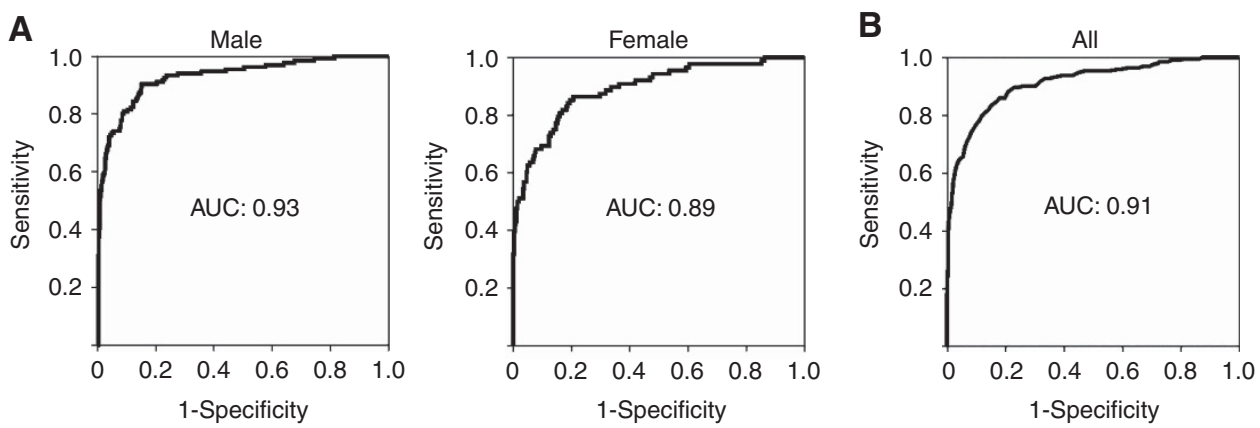

Figure 3. ROC analysis of GTA-446 levels. (A) In CRC and control groups by gender (left, males; right, females). (B) Result of multiple logistic regression analysis in which GTA-446 level and gender were used as variables. 
CA19-9, well-known tumour markers of CRC, are known to be affected by gender. Previous studies reported that a higher proportion of women than men are diagnosed with right-sided colon cancer, which tends to be more malignant with high microsatellite instability and worse prognosis (Benedix et al, 2010; Missiaglia et al, 2014). In addition, the difference in hormonal status or expression of hormone receptor according to gender has been focused on in the development of CRC (Murphy et al, 2011; Majek et al, 2013). On the basis of these studies, it is conceivable that various factors such as those mentioned above are intricately involved, leading to the gender difference in the field of metabolomics. Aging and dietary habits could also be other possible factors influencing metabolism, as investigated in our previous reports. We revealed that GTA-446 levels decrease slightly with age in healthy people, whereas GTA-446 is downregulated at any age in CRC patients compared with the older healthy people (Ritchie et al, 2010b). We also reported that the intra-individual GTA-446 levels are relatively stable and resistant to acute lifestyle factors, such as dietary habits (Ritchie et al, 2010b).

One limitation of this study is that sporadic CRC generally follows an adenoma-carcinoma sequence, whereas colitic cancer follows a dysplasia-carcinoma sequence (Walther et al, 2009; Matkowskyj et al, 2013; West et al, 2015). The CRC group was composed of patients with either sporadic or colitic cancer, and we did not analyse the two cancer forms independently. To determine whether GTA-446 is a predictive marker for both types of cancer, patients with inflammatory bowel disease may have to be distinguished from other types of patients. In addition, patients with genetic cancer were not included in this study. It is possible that genetic CRC exhibits different GTA-446 trends, and further investigation of this issue should be clarified in the next step. Furthermore, the control group reflected a normal healthy cohort, but we did not definitively prove that they had no CRC or precancerous lesions by total colonoscopy. Therefore, there may have been CRC patients among the healthy cohort, and selection bias may have been involved. A large-scale prospective cohort study designed to eliminate sources of bias and to confirm that GTA-446 levels can be used as a primary screening tool in healthy people is required.

In conclusion, we demonstrated the clinical feasibility of GTA446 in CRC screening. This predictive marker has high sensitivity when cut-off values are set according to gender. GTA-446 is a promising tool for primary CRC screening with the goal of early detection to identify populations at higher risk of CRC and requiring detailed examination.

\section{CONFLICT OF INTEREST}

The authors declare no conflict of interest.

\section{REFERENCES}

Abbasi O, Mashayekhi F, Mirzajani E, Fakhriyeh Asl S, Mahmoudi T, Saeedi Saedi H (2015) Soluble VEGFR1 concentration in the serum of patients with colorectal cancer. Surg Today 45(2): 215-220.

Ahlquist DA, Skoletsky JE, Boynton KA, Harrington JJ, Mahoney DW, Pierceall WE, Thibodeau SN, Shuber AP (2000) Colorectal cancer screening by detection of altered human DNA in stool: feasibility of a multitarget assay panel. Gastroenterology 119(5): 1219-1227.

Ahlquist DA, Zou H, Domanico M, Mahoney DW, Yab TC, Taylor WR, Butz ML, Thibodeau SN, Rabeneck L, Paszat LF, Kinzler KW, Vogelstein B, Bjerregaard NC, Laurberg S, Sorensen HT, Berger BM, Lidgard GP (2012) Next-generation stool DNA test accurately detects colorectal cancer and large adenomas. Gastroenterology 142(2): 248-256.
Allison JE, Tekawa IS, Ransom LJ, Adrain AL (1996) A comparison of fecal occult-blood tests for colorectal-cancer screening. N Engl J Med 334(3): 155-159.

Benedix F, Kube R, Meyer F, Schmidt U, Gastinger I, Lippert H, Colon/Rectum Carcinomas Study Group (2010) Comparison of 17,641 patients with right- and left-sided colon cancer: differences in epidemiology, perioperative course, histology, and survival. Dis Colon Rectum 53(1): 57-64.

Brenner H, Kloor M, Pox CP (2014) Colorectal cancer. Lancet 383(9927): 1490-1502.

Budinska E, Popovici V, Tejpar S, D’Ario G, Lapique N, Sikora KO, Di Narzo AF, Yan P, Hodgson JG, Weinrich S, Bosman F, Roth A, Delorenzi M (2013) Gene expression patterns unveil a new level of molecular heterogeneity in colorectal cancer. J Pathol 231(1): 63-76.

De Sousa EMF, Wang X, Jansen M, Fessler E, Trinh A, de Rooij LP, de Jong JH, de Boer OJ, van Leersum R, Bijlsma MF, Rodermond $\mathrm{H}$, van der Heijden M, van Noesel CJ, Tuynman JB, Dekker E, Markowetz F, Medema JP, Vermeulen L (2013) Poor-prognosis colon cancer is defined by a molecularly distinct subtype and develops from serrated precursor lesions. Nat Med 19(5): 614-618.

Green RJ, Metlay JP, Propert K, Catalano PJ, Macdonald JS, Mayer RJ, Haller DG (2002) Surveillance for second primary colorectal cancer after adjuvant chemotherapy: an analysis of Intergroup 0089. Ann Intern Med 136(4): 261-269.

Guinney J, Dienstmann R, Wang X, de Reynies A, Schlicker A, Soneson C, Marisa L, Roepman P, Nyamundanda G, Angelino P, Bot BM, Morris JS, Simon IM, Gerster S, Fessler E, De Sousa EMF, Missiaglia E, Ramay H, Barras D, Homicsko K, Maru D, Manyam GC, Broom B, Boige V, PerezVillamil B, Laderas T, Salazar R, Gray JW, Hanahan D, Tabernero J, Bernards R, Friend SH, Laurent-Puig P, Medema JP, Sadanandam A, Wessels L, Delorenzi M, Kopetz S, Vermeulen L, Tejpar S (2015) The consensus molecular subtypes of colorectal cancer. Nat Med 21(11): $1350-1356$.

Hardcastle JD, Chamberlain JO, Robinson MH, Moss SM, Amar SS, Balfour TW, James PD, Mangham CM (1996) Randomised controlled trial of faecal-occult-blood screening for colorectal cancer. Lancet 348(9040): $1472-1477$.

Imperiale TF, Ransohoff DF, Itzkowitz SH, Levin TR, Lavin P, Lidgard GP, Ahlquist DA, Berger BM (2014) Multitarget stool DNA testing for colorectal-cancer screening. N Engl J Med 370(14): 1287-1297.

Imperiale TF, Ransohoff DF, Itzkowitz SH, Turnbull BA, Ross ME, Colorectal Cancer Study Group (2004) Fecal DNA versus fecal occult blood for colorectal-cancer screening in an average-risk population. $N$ Engl J Med 351(26): 2704-2714.

Kim SE, Paik HY, Yoon H, Lee JE, Kim N, Sung MK (2015) Sex- and genderspecific disparities in colorectal cancer risk. World J Gastroenterol 21(17): 5167-5175.

Kim Y, Lee S, Park S, Jeon H, Lee W, Kim JK, Cho M, Kim M, Lim J, Kang CS, Han K (2003) Gastrointestinal tract cancer screening using fecal carcinoembryonic antigen. Ann Clin Lab Sci 33(1): 32-38.

Kronborg O, Fenger C, Olsen J, Jorgensen OD, Sondergaard O (1996) Randomised study of screening for colorectal cancer with faecal-occultblood test. Lancet 348(9040): 1467-1471.

Ma Y, Peng J, Liu W, Zhang P, Huang L, Gao B, Shen T, Zhou Y, Chen H, Chu Z, Zhang M, Qin H (2009) Proteomics identification of desmin as a potential oncofetal diagnostic and prognostic biomarker in colorectal cancer. Mol Cell Proteomics 8(8): 1878-1890.

Majek O, Gondos A, Jansen L, Emrich K, Holleczek B, Katalinic A, Nennecke A, Eberle A, Brenner H. Group GCSW (2013) Sex differences in colorectal cancer survival: population-based analysis of 164,996 colorectal cancer patients in Germany. PLoS One 8(7): e68077.

Mandel JS, Bond JH, Church TR, Snover DC, Bradley GM, Schuman LM, Ederer F (1993) Reducing mortality from colorectal cancer by screening for fecal occult blood. Minnesota Colon Cancer Control Study. N Engl J Med 328(19): 1365-1371.

Marisa L, de Reynies A, Duval A, Selves J, Gaub MP, Vescovo L, Etienne-Grimaldi MC, Schiappa R, Guenot D, Ayadi M, Kirzin S, Chazal M, Flejou JF, Benchimol D, Berger A, Lagarde A, Pencreach E, Piard F, Elias D, Parc Y, Olschwang S, Milano G, Laurent-Puig P, Boige V (2013) Gene expression classification of colon cancer into molecular subtypes: characterization, validation, and prognostic value. PLoS Med 10(5): e1001453. 
Matkowskyj KA, Chen ZE, Rao MS, Yang GY (2013) Dysplastic lesions in inflammatory bowel disease: molecular pathogenesis to morphology. Arch Pathol Lab Med 137(3): 338-350.

Missiaglia E, Jacobs B, D'Ario G, Di Narzo AF, Soneson C, Budinska E, Popovici V, Vecchione L, Gerster S, Yan P, Roth AD, Klingbiel D, Bosman FT, Delorenzi M, Tejpar S (2014) Distal and proximal colon cancers differ in terms of molecular, pathological, and clinical features. Ann Oncol 25(10): 1995-2001.

Muller HM, Oberwalder M, Fiegl H, Morandell M, Goebel G, Zitt M, Muhlthaler M, Ofner D, Margreiter R, Widschwendter M (2004) Methylation changes in faecal DNA: a marker for colorectal cancer screening? Lancet 363(9417): 1283-1285.

Murphy G, Devesa SS, Cross AJ, Inskip PD, McGlynn KA, Cook MB (2011) Sex disparities in colorectal cancer incidence by anatomic subsite, race and age. Int J Cancer 128(7): 1668-1675.

Ritchie SA, Ahiahonu PW, Jayasinghe D, Heath D, Liu J, Lu Y, Jin W, Kavianpour A, Yamazaki Y, Khan AM, Hossain M, Su-Myat KK, Wood PL, Krenitsky K, Takemasa I, Miyake M, Sekimoto M, Monden M, Matsubara H, Nomura F, Goodenowe DB (2010a) Reduced levels of hydroxylated, polyunsaturated ultra long-chain fatty acids in the serum of colorectal cancer patients: implications for early screening and detection. BMC Med 8: 13.

Ritchie SA, Heath D, Yamazaki Y, Grimmalt B, Kavianpour A, Krenitsky K, Elshoni H, Takemasa I, Miyake M, Sekimoto M, Monden M, Tomonaga T, Matsubara H, Sogawa K, Matsushita K, Nomura F, Goodenowe DB (2010b) Reduction of novel circulating long-chain fatty acids in colorectal cancer patients is independent of tumor burden and correlates with age. BMC Gastroenterol 10: 140.

Ritchie SA, Jayasinghe D, Davies GF, Ahiahonu P, Ma H, Goodenowe DB (2011) Human serum-derived hydroxy long-chain fatty acids exhibit antiinflammatory and anti-proliferative activity. J Exp Clin Cancer Res 30: 59

Ritchie SA, Tonita J, Alvi R, Lehotay D, Elshoni H, Myat S, McHattie J, Goodenowe DB (2013) Low-serum GTA-446 anti-inflammatory fatty acid levels as a new risk factor for colon cancer. Int J Cancer 132(2): 355-362.

Roepman P, Schlicker A, Tabernero J, Majewski I, Tian S, Moreno V, Snel MH, Chresta CM, Rosenberg R, Nitsche U, Macarulla T, Capella G, Salazar R, Orphanides G, Wessels LF, Bernards R, Simon IM (2014) Colorectal cancer intrinsic subtypes predict chemotherapy benefit, deficient mismatch repair and epithelial-to-mesenchymal transition. Int $J$ Cancer 134(3): 552-562.

Sadanandam A, Lyssiotis CA, Homicsko K, Collisson EA, Gibb WJ, Wullschleger S, Ostos LC, Lannon WA, Grotzinger C, Del Rio M, Lhermitte B, Olshen AB, Wiedenmann B, Cantley LC, Gray JW, Hanahan D (2013) A colorectal cancer classification system that associates cellular phenotype and responses to therapy. Nat Med 19(5): 619-625.

Schlicker A, Beran G, Chresta CM, McWalter G, Pritchard A, Weston S, Runswick S, Davenport S, Heathcote K, Castro DA, Orphanides G, French T, Wessels LF (2012) Subtypes of primary colorectal tumors correlate with response to targeted treatment in colorectal cell lines. BMC Med Genomics 5: 66.

Solmi R, Ugolini G, Rosati G, Zanotti S, Lauriola M, Montroni I, del Governatore M, Caira A, Taffurelli M, Santini D, Coppola D, Guidotti L, Carinci P, Strippoli P (2006) Microarray-based identification and RT-PCR test screening for epithelial-specific mRNAs in peripheral blood of patients with colon cancer. BMC Cancer 6: 250.

Song K, Fendrick AM, Ladabaum U (2004) Fecal DNA testing compared with conventional colorectal cancer screening methods: a decision analysis. Gastroenterology 126(5): 1270-1279.

Srivastava S, Verma M, Henson DE (2001) Biomarkers for early detection of colon cancer. Clin Cancer Res 7(5): 1118-1126.

Toiyama Y, Tanaka K, Inoue Y, Mohri Y, Kusunoki M (2016) Circulating cell-free microRNAs as biomarkers for colorectal cancer. Surg Today 46(1): 13-24.

Tokunaga R, Sakamoto Y, Nakagawa S, Yoshida N, Baba H (2017) The utility of tumor marker combination, including serum P53 antibody, in colorectal cancer treatment. Surg Today 47(5): 636-642.

Torre LA, Bray F, Siegel RL, Ferlay J, Lortet-Tieulent J, Jemal A (2015) Global cancer statistics, 2012. CA Cancer J Clin 65(2): 87-108.

Toth K, Sipos F, Kalmar A, Patai AV, Wichmann B, Stoehr R, Golcher H, Schellerer V, Tulassay Z, Molnar B (2012) Detection of methylated SEPT9 in plasma is a reliable screening method for both left- and right-sided colon cancers. PLoS One 7(9): e46000.

Walther A, Johnstone E, Swanton C, Midgley R, Tomlinson I, Kerr D (2009) Genetic prognostic and predictive markers in colorectal cancer. Nat Rev Cancer 9(7): 489-499.

West NR, McCuaig S, Franchini F, Powrie F (2015) Emerging cytokine networks in colorectal cancer. Nat Rev Immunol 15(10): 615-629.

Winawer S, Fletcher R, Rex D, Bond J, Burt R, Ferrucci J, Ganiats T, Levin T, Woolf S, Johnson D, Kirk L, Litin S, Simmang C, Gastrointestinal Consortium Panel (2003) Colorectal cancer screening and surveillance: clinical guidelines and rationale: update based on new evidence. Gastroenterology 124(2): 544-560.

Yoshioka Y, Kosaka N, Konishi Y, Ohta H, Okamoto H, Sonoda H, Nonaka R, Yamamoto H, Ishii H, Mori M, Furuta K, Nakajima T, Hayashi H, Sugisaki H, Higashimoto H, Kato T, Takeshita F, Ochiya T (2014) Ultra-sensitive liquid biopsy of circulating extracellular vesicles using ExoScreen. Nat Commun 5: 3591.

Zauber AG, Winawer SJ, O'Brien MJ, Lansdorp-Vogelaar I, van Ballegooijen M, Hankey BF, Shi W, Bond JH, Schapiro M, Panish JF, Stewart ET, Waye JD (2012) Colonoscopic polypectomy and long-term prevention of colorectal-cancer deaths. N Engl J Med 366(8): 687-696.

This work is published under the standard license to publish agreement. After 12 months the work will become freely available and the license terms will switch to a Creative Commons AttributionNonCommercial-Share Alike 4.0 Unported License. 